BULLETIN Bulletin hispanique

HISPANIQUE Université Michel de Montaigne Bordeaux

120-1 | 2018

Varia

Julio Peñate Rivero (ed.), Espacio insular y creación literaria: Antillas, Baleares, Canarias

Madrid, Editorial Verbum, Colección Ensayo, 2017

Geneviève Champeau

\title{
OpenEdition
}

Journals

Edición electrónica

URL: https://journals.openedition.org/bulletinhispanique/6336

DOI: 10.4000/bulletinhispanique.6336

ISSN: 1775-3821

Editor

Presses universitaires de Bordeaux

Edición impresa

Fecha de publicación: 30 junio 2018

Paginación: 375-379

ISBN: 979-10-300-0298-0

ISSN: 0007-4640

Referencia electrónica

Geneviève Champeau «Julio Peñate Rivero (ed.), Espacio insular y creación literaria: Antillas, Baleares,

Canarias», Bulletin hispanique [En línea], 120-1 | 2018, Publicado el 30 junio 2018, consultado el 08 enero 2022. URL: http://journals.openedition.org/bulletinhispanique/6336 ; DOI: https://doi.org/ 10.4000/bulletinhispanique.6336

Este documento fue generado automáticamente el 8 enero 2022.

Tous droits réservés 


\section{Julio Peñate Rivero (ed.), Espacio insular y creación literaria: Antillas, Baleares, Canarias}

Madrid, Editorial Verbum, Colección Ensayo, 2017

\section{Geneviève Champeau}

\section{REFERENCIA}

Julio Peñate Rivero (ed.), Espacio insular y creación literaria: Antillas, Baleares, Canarias. Madrid, Editorial Verbum, Colección Ensayo, 2017, 338 pp. -ISBN: 978-84-9074-523-6.

1 Retornando a sus orígenes insulares, Julio Peñate coordina un libro dedicado a la literatura de tres archipiélagos del ámbito hispano, las Antillas, Baleares y Canarias, fruto de un programa de investigación que se llevó a cabo en la universidad de Friburgo (Suiza). Después de una consistente introducción de J. Peñate, cada uno de los tres apartados dedicados a las entidades mencionadas reúne estudios generales y el análisis de una obra. El cuarto presenta textos originales de seix escritores -José L. Correa, Oswaldo Guerra y Francisco J. Quevedo (Canarias), Enric Valentí Puig y Carme Riera (Mallorca), Pío E. Serrano (Cuba)- que intervienen sucesivamente como investigadores y escritores, llevándose la parte del león.

2 ¿Cómo no tener en cuenta las peculiaridades de los tres archipiélagos? Mientras que Baleares pertenece al Mediterráneo, cuna y encrucijada de antiguas civilizaciones occidentales que han ido depositando en su imaginario sucesivos estratos a lo largo del tiempo (Pilar Arnau 156; Valentí Puig, 163; Tatiana Molina, 197), las Antillas y Canarias están situadas en el mar de la Modernidad, dialogan con otros continentes, África y América y padecieron el trauma de la conquista española que destruyó sus poblaciones originarias, introdujo el mestizaje de su población, su cultura, incluso de su lengua, transformó su economía y las mantuvo en una situación de dependencia económica, cultural y política (cf. Julio Peñate, 93-114; Oswaldo Guerra, 209-229). Transcendiendo 
estas diferencias el libro rastrea constantes en la concepción de la insularidad, en la plasmación del paisaje y de la historia, interrogándose sobre motivos descriptivos y narrativos, incluso rasgos estilísticos recurrentes. «i[s]e puede hablar de una narrativa insular -pregunta Natalia Oberli-, con una serie de elementos comunes, coherentes y significativos que la distingan de las demás?».

3 Las representaciones de las islas suelen proceder de una mirada exterior, de un imaginario continental en el cual son el objetivo de un viaje, el inicio de una aventura, un refugio o un lugar poblado de seres diabólicos. Este libro invierte la perspectiva dedicándose a miradas autóctonas, si se considera que es aún mirada «desde dentro» la de escritores exiliados (caso cubano) o que, viviendo en una metrópoli como Carmen Riera y Valentí Puig, afincados en Barcelona, conservan potentes lazos con su isla natal. Estas miradas autóctonas se construyen en una relación de asimilación parcial y rechazo de los tópicos elaborados y difundidos desde fuera (Pilar Arnau, 141-160), «desde la fascinación y la extrañeza» (Pío E. Serrano, 30). Desde dentro, las islas dejan de ser lo otro ${ }^{1}$, el espacio del viaje, la aventura, la utopía o la distopia para pasar a ser condicionante de la identidad. En esta perspectiva, se destacan tres constantes en la literatura de las diferentes áreas: una tensión entre aislamiento y tránsito, entre margen y metropoli y entre isla y archipiélago.

4 Las islas poseen una frontera marítima «primordial» (Julio Peñate, 19), «inesquivable» (Enric Vicent Sorià, 173) que, más que otras terrestres, como lo enuncia la misma lengua, «aísla». Las contribuciones destacan una concepción ambivalente del mar que une tanto como separa. El mar es en efecto espacio de tránsito: de una isla a otra, de la isla al continente, en las rutas marítimas. Se hace hincapié en la función de puente que desempeñaron Cuba y Canarias en el comercio triangular, en la situación de Canarias entre tres contienentes -Europa, África y América- (Julio Peñate, 12, Pío E. Serrano, 31) $\mathrm{y}$ en las afinidades que unen islas de ambos extremos del Atlántico hasta tal punto que el novelista Armas Marcelo crea un transunto de una isla canaria que "evidencia el trasiego canario-americano hasta convertir[lo] en dos extremidades del mismo territorio» (F. J. Quevedo, 248); y en $\mathrm{El}$ árbol del bien y del mal, uno de sus personajes «cruzaba el Atlántico con la sensación de propiedad de quien sale de su cuarto de dormir y atraviesa un largo pasillo azul para entrar en otra habitación de la misma casa» (citado por F. J. Quevedo, 249). Una «atlanticidad cultural» (Pío E. Serrano, 29 y 37) debida a una similar condición de islas conquistadas, dependientes económica, social y culturalmente de una o varias metrópolis, cuya evolución secular es «más bien propia de formaciones sociales periféricas» subordinadas a un «centro impulsor» (Julio Peñate, 93-108). Aunque circunstancias históricas comunes fraguaron vínculos peculiares entre las islas del Atlántico, también en Baleares comprueba Valentí Puig la presencia de la dualidad simbólica de un «mundo [insular] a la vez hermético y paradójicamente abierto» (170).

5 La tensión entre ensimismamiento y apertura lleva a los contribuidores de este estudio a considerar, por una parte, la relación entre isla y archipiélago. Una de las diferencias que subraya el libro entre la mirada desde dentro y la mirada foránea es que la primera usa el sustantivo «isla» en plural, haciendo hincapié en la peculiaridad de cada una, frente a la visión unitaria del archipiélago más propia de los continentales. «Disimilitudes geográficas e incluso históricas -explica Valentí Puig- dificultan la generalización de un concepto de lo balear, es decir, del archipiélago como comunidad cohesiva, con una cierta conciencia de comunidad interinsular» (163; ver también Enric 
Vicent Sorià,173). «El concepto de "archipiélago" -escribe Ernst Rudin- es metáforica y literariamente mucho menos fructífero que el de "isla"» (51). Es que los escritores isleños privilegian los lazos que los unen a la metópoli a las relaciones con las entidades geográficas más próximas. Es particularmente patente en el caso de las Antillas, el archipiélago más heterogéneo (Pío E. Serrano, 27-30). La historia de Cuba y Puerto Rico ha llevado a sus escritores a tematizar la relación de estas islas con el potente vecino del norte mientras que el exilio de los disidentes cubanos conduce a distinguir una literatura "del interior" y otra "del exterior".

Cabe añadir a estas convergencias históricas, sociológicas y culturales otra de tipo literario. Siendo espacios estrictamente limitados y de dimensiones reducidas, las islas tienden a considerarse como microcosmos, metáforas del mundo (J. Peñate, 10) que condensan la significación: «en la insularidad los hechos esenciales adquieren una intensidad especial, una definición, una delimitación de cualidades que no se hallan en tierras continentales», explica Valentí Puig (166). Puede reforzar esta dimensión metonímica de la isla un encaje de microcosmos, a modo de cajas chinas, cuando una institución, casa, una familia, condensan la representación de la sociedad isleña, lo que ilustran La casa de la laguna de la puertoriqueña Rosario Ferré (Juana C. Goop, 130-131) y Tiempo de inocencia de Carme Riera (Tatiana Molina, 188, 192-193, 195).

¿Bastan estas convergencias para manifestar esa «sensibilidad diferente de las islas» a la que alude Lezama Lima? A ello sa ha de añadir, según los contribuyentes, el papel decisivo del espacio en la búsqueda literaria de lo que diferencia y caracteriza la isla destacando dos ingredientes: la construcción del paisaje y la mitificación de la historia.

«El espacio se convierte en algo cardinal a falta de una lengua propia y distinta de la española» recalca José L. Correa (265). Incluso para quien se ha alejado de su isla natal, como Carme Riera, el paisaje mallorquín sigue siendo parte de su identidad. «Desde muy pequeña -declara en el relato insertado al final del libro- me he sentido fuertemente ligada a un determinado paisaje de la costa norte mallorquina donde pasé parte de la infancia y al que siempre, año tras año, necesito volver porque nunca me he ido» (323). En su cuestionamiento de la propia identidad, la literatura isleña reciente compagina la exaltación tópica de las bellezas naturales -a veces idealizadas desde el exilio- y su cuestionamiento: retorno desilusionante, realidad social, confinamiento, estragos del turismo, etc. (Pilar Arnau, 155-159).

9 Al componente autobiográfico y de la «sintaxis del mar» (215), añaden las contribuciones un componente mítico. El canario Oswaldo Guerra expone cómo la construcción del paisaje se aleja, en sus obras, del logocentrismo cultural helenístico para privilegiar espacios simbólicos enraizados en la geografía local y un imaginario prehispano: la selva, el volcán (210). El mito se acerca al tópico en la integración de ciertos personajes históricos asociados a determinados lugares: George Sand y Chopin en Valdemossa, el Archiduque Luis Salvador de Habsburgo-Lorena en la Serra de Tramuntana, en la literatura mallorquina (Pilar Arnau, 149). En Canarias, es la «castración histórica» consecutiva a la conquista española lo que llevó a fijar algunas invariantes en la evocación del paisaje, entre las cuales la cueva-yacija asociada a sedimentos históricos, a la historia de los guanches (Oswalso Guerra, 218-227). Observa el escritor que, a pesar de la internacionalización de las culturas y el desarrollo de redes de información, algunos escritores, en su afán identitario, exacerban la mitificación del paisaje que sustituye a una perspectiva histórica «un sueño permanente» (228-229). Inversamente, también existe una tendencia centrífuga entre escritores isleños que van 
ampliando horizontes, alejándose cada vez más del marco de la geografía isleña : «[1]a insularidad como espacio de reflexión ha disminuido en esta literatura [caso balear] a medida que han aumentado las facilidades para viajar, para sentirse parte del mundo de fuera» (Pilar Arnau, 159). Frente a una literatura atenta a la tradición local, a lo que une a la comunidad, otra literatura, más individualista, se abre al exterior (Julio Peñate, 15; Enric Vicent Sorià, 177-178).

Si bien es convincente la presentación ciertas constantes interisleñas, la pertinencia del marbete «literatura insular», o mejor dicho, en palabras de Enric Vicent Sorià, la cuestión de saber si se puede identificar «una literatura propia en el idioma común» (179) parece más problemática. Primero, porque solo se examina en este trabajo una producción literaria procedente de un mismo ámbito cultural, el hispano. Haría falta compararla con los resultados de trabajos similares dedicados a otros ámbitos culturales para sacar conclusiones. En segundo lugar, hay rasgos que comparten solo las islas oceánicas. Tercero: otros rasgos destacados no parecen exclusivos de los espacios insulares, como sentirse distinto o conceder mucha importancia al espacio de la infancia; otros parecen más bien propios de un solo archipiélago, cuando José L. Correa destaca un «acento» que suele habitar la literatura canaria, la socarronería (263). Tampoco es proprio de la literatura de las islas el multilingüismo manifiesto en la práctica de la autotraducción por la puertoriqueña Rosario Ferré, que escribió primero en inglés su novela La casa de la laguna (Juana C. Goop, 138), y por Carme Riera que hizo lo mismo con el mallorquín en su relato autoficcional Tiempo de inocencia (Tatiana Molina, 200). Verdad es que los autores de este libro se muestran muy prudentes y lo que hacen es avanzar una propuesta sin darle una respuesta categórica. La discusión queda abierta.

\section{NOTAS}

1. Según Enric Vient Sorià, los escritores isleños, poco conocidos fuera de sus islas, siguen siendo, sin embargo, «raros» para el lector continental, «da[n] la nota discordante» (177).

\section{AUTORES}

\section{GENEVIÈVE CHAMPEAU}

Université Bordeaux Montaigne 